\title{
Design and simulation of high purity biodiesel reactive distillation process
}

\author{
Syed Sadiq Ali ${ }^{1, *}$, Mohammad Asif ${ }^{2}$, Avijit Basu ${ }^{1}$ \\ ${ }^{1}$ Department of Chemical Engineering, King Faisal University, PO Box 380, Al-Ahsa 31982, Saudi Arabia \\ ${ }^{2}$ Department of Chemical Engineering, King Saud University, PO Box 800, Riyadh 11421, Saudi Arabia \\ "Corresponding author: e-mail: ssali@kfu.edu.sa
}

\begin{abstract}
Biodiesel is a promising energy substitute of fossil fuels since it is produced from renewable and biodegradable sources. In the present work, reactive distillation (RD) process is designed and simulated using Aspen Plus process simulator to produce biodiesel of high purity through esterification reaction. The simultaneous reaction and separation in same unit enhances the biodiesel yield and composition in RD process. Two flowsheets are proposed in present work. In the first flowsheet, the unreacted methanol is recycled back to reactive distillation column. Biodiesel with $99.5 \mathrm{~mol} \%$ purity is obtained in product stream while the byproduct stream comprises $95.2 \mathrm{~mol} \%$ water, which has to be treated further. In the second flowsheet, a part of methanol recycle is split and purged. In this case, the biodiesel composition in product stream is $99.7 \mathrm{~mol} \%$ whereas water composition is $99.9 \mathrm{~mol} \%$ in byproduct stream, which can be reused for other process without treatment.
\end{abstract}

Keywords: biodiesel, reactive distillation, process simulator, recycle, purge.

\section{INTRODUCTION}

Energy demands are steadily increasing on day-to-day basis for the sustenance and development of human race, which has resulted in rapid depletion of non-renewable energy reserves and high-energy costs. Hence, researchers, in the recent past, have highly emphasized on renewable energy sources, which are nontoxic, biodegradable and environment friendly ${ }^{1-4}$.

Biodiesel is a prominent alternative of petroleum diesel used worldwide ${ }^{3}$. It is a clean-burning renewable fuel, which has similar properties as petroleum diesel. Biodiesel is mainly composed of fatty acid mono-alkyl esters, which are produced by the transesterification reaction of alcohol and free fatty acids (FFA), derived from renewable resources such as vegetable oils, waste cooking-oils or animal fats ${ }^{2,4}$. However, the byproduct 'water' formed in transesterification reaction makes the reaction rate sluggish, which results in high residence time, low biodiesel yield and purity in a conventional process. Moreover, separation and purification of biodiesel further add up to the process cost economics ${ }^{5,6}$.

Reactive distillation (RD) is a well-known process, particularly attractive for equilibrium-limited chemical reactions, where the reaction and separation occur concurrently in the same unit, thereby separating the product simultaneously after reaction and shift the reaction equilibrium towards higher products yield and composition ${ }^{7}$. The RD process lowers the overall capital and operational costs since a single unit is required for reaction and separation rather than two separate process units. Moreover, the heat generated during exothermic reaction can be efficiently utilized to improve the heat economy of the system ${ }^{8}$.

The compactness and cost-effectiveness of RD processes make them ideally suited for several industrial applications, like petrochemicals industries ${ }^{9,10}$ and, processes such as alkylation, acetalization, and especially esterification $^{10-12}$. The RD process is widely used for the production of biodiesel by esterification ${ }^{13-17}$. Kiss et al. ${ }^{18}$ performed experimental studies of biodiesel production by esterification reaction using sulfated zirconia catalyst. They varied various process parameters such as catalyst weight percentage, molar feed ratio, process temperature, and pressure and derived the overall acid conversion. Further, they proposed a RD process and studied the model with similar process parameters. They found that the biodiesel productivity is enhanced up to $6-10$ times by using RD process over conventional process. Researchers have proposed various process flowsheets using RD process to produce biodiesel with high yield and composition. Nguyen and Demirel ${ }^{15}$ used a RD column and a distillation column in their Aspen Plus simulations, which were thermally coupled. The energy consumptions reduced by $13.1 \%$ and $50 \%$ respectively in both columns. The biodiesel obtained has purity of $95.8 \mathrm{~mol} \%$ while water purity was $98.8 \mathrm{~mol} \%$. Agarwal et $\mathrm{al}^{14}$ performed simulation studies of RD process for biodiesel production using Matlab and CHEMCAD software. The proposed RD model achieved up to $97 \%$ triglycerides conversion and $90.3 \%$ yield. Machado et a ${ }^{19}$ performed computer simulations to produce biodiesel from fatty organic acids by hydro-esterification. They conducted hydrolysis reaction in packed bed reactor while esterification was performed in RD column. The water produced in the RD column was recycled back to packed bed reactor for hydrolysis reaction. The biodiesel purity achieved was up to 99 mol\%. Bildea and Kiss ${ }^{20}$ performed Aspen Plus simulations using RD column with decanter and flash column in the process flowsheet. They obtained biodiesel of purity $99.1 \mathrm{~mol} \%$ while water purity was $99.99 \mathrm{~mol} \%$. They further performed dynamic analysis and proposed a control scheme to control process parameters and maintain product quality. Researchers have also proposed the use of dual RD columns to further increase biodiesel yield and purity ${ }^{21,22}$. Cisneros et $\mathrm{al}^{22}$ used integrated dual RD columns in series in their simulations. After intense process optimization in Aspen Plus process simulator, they obtained biodiesel product of $99.92 \mathrm{~mol} \%$ and water purity of $99.97 \mathrm{~mol} \%$. Moreover, researchers have also proposed heat integration techniques and thermally coupled RD process to enhance the efficiency of RD columns ${ }^{13,15,23}$. Although, $\mathrm{RD}$ processes produce high purity biodiesel, the purity 
of byproduct, water, is significant as well, to reduce the water treatment and processing costs.

In the present work, reactive distillation process is used for the production of fatty acid methyl esters (FAME) of high purity $(>99.5 \%)$ using methanol and lauric acid (dodecanoic acid), which is a common FFA, as feed. The process flowsheet was designed and simulated in steady state using Aspen Plus V9 process simulator. Moreover, the flowsheet simulations were further carried out after undergoing minor modifications in the process flowsheet in order to increase the mole purity of byproduct water up to $99.9 \mathrm{~mol} \%$. Methanol feed molar flow rate was set to $5 \%$ excess to lauric acid feed. The process operation with equal molar feed rate requires high sensitive and precise composition analyzers and flowmeters as part of process control system since any imbalance in stoichiometry may compromise the product formation rate and product purity. These composition analyzers are expensive and involve complex operation and maintenance ${ }^{24}$. Excess reactant process eliminates the need of equal feed rates, which makes process control primitive for RD systems. Therefore, industrial RD process often employ one excess reactant than the required stoichiometric number to simplify RD process control system ${ }^{25}$. However, excess reactant process often employs an extra distillation column to separate excess reactant that can be recycled back to RD column. The addition of column increases the capital and operational costs of process plant, albeit, proper heat integration of RD column and distillation column can result in less energy intensive process than single RD column process $^{\mathbf{1 3}}{ }^{\mathbf{2 1}}$. We have proposed two process flowsheets in the present work. Both process flowsheets consist of RD column followed by distillation column to recover unreacted methanol. All the excess methanol recovered is recycled back in the first process flowsheet while a portion of recycle is split as purge in the second flowsheet in order to obtain byproduct water of high purity, keeping in mind, that further water treatment process is highly cost inclusive process. The composition of water in the byproduct increased up to $99.9 \mathrm{~mol} \%$, while performing minimal change in process design by adding a splitter in process flowsheet in the present work.

\section{PROBLEM STATEMENT}

Production of high purity biodiesel at industrial scale is a major challenge in process industries ${ }^{\mathbf{2 6}}$. In the present work, reactive distillation process is used to produce $12.39 \mathrm{kton} /$ year of methyl-dodecanoate (FAME) of up to $99.5 \%$ purity using heterogeneous acid solid catalysts $^{27}$. Methanol and dodecanoic acid (FFA) were used as reactants. Methanol molar flow rate was kept at $5 \%$ excess of acid feed in order to circumvent from complicated control process and costly and complex composition analyzers. Two process flowsheets, Case $\mathrm{A}$ and Case B, were designed and studied by varying various process parameters. The steady state process flowsheet simulations were performed in Aspen Plus V9 process simulator. The process flowsheets comprise of dual distillation columns; the first is RD column where reaction and separation takes place simultaneously and the second distillation column is used to separate excess unreacted reactant from byproducts. The process flow diagram of Case $\mathrm{A}$ is shown in Fig. 1. The distillate from second column, which mainly constitutes methanol and water, is recycled and mixed with fresh methanol feed in a mixer and connected further to RD column as feed. The process flow diagram for Case B is drawn in Fig. 2. A splitter is attached to the distillate stream exiting from Column 2, which separates a portion of effluent from distillate as purge and recycles back the remaining effluent which is further mixed with fresh methanol as in Case A. The purge split fraction was set at $8.0 \mathrm{~mol} \%$. The configuration of RD column and second column is reported in Table 1 . The design parameters in Table 1 were set identical for both process configurations in Case $\mathrm{A}$ and Case B. The reactive stages were Stages 16-20

Table 1. Columns configurations of biodiesel production process similar for Case A and Case B

\begin{tabular}{|l|c|c|}
\hline & RD column & Column 2 \\
\hline Number of stages & 18 & 10 \\
\hline Reactive stages & $6-15$ & - \\
\hline $\begin{array}{l}\text { Operating } \\
\text { pressure }\end{array}$ & $6 \mathrm{bar}$ & $3 \mathrm{bar}$ \\
\hline Column diameter & $0.71 \mathrm{~m}$ & $0.3 \mathrm{~m}$ \\
\hline Column height & $9.75 \mathrm{~m}$ & $4.88 \mathrm{~m}$ \\
\hline Liquid hold up & $20 \mathrm{I}$ & - \\
\hline Feed stage & Above 6 and 16 & 7 \\
\hline
\end{tabular}

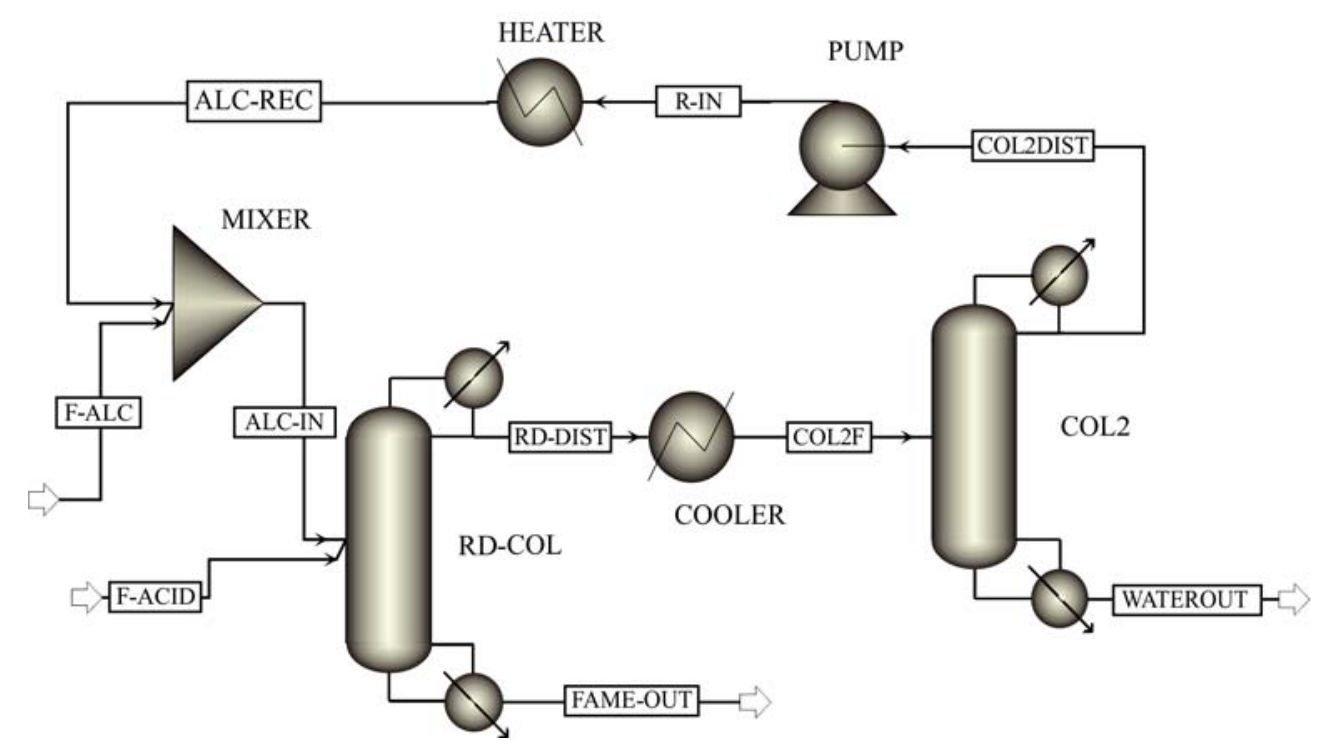

Figure 1. Process flow diagram of biodiesel production process for Case A 


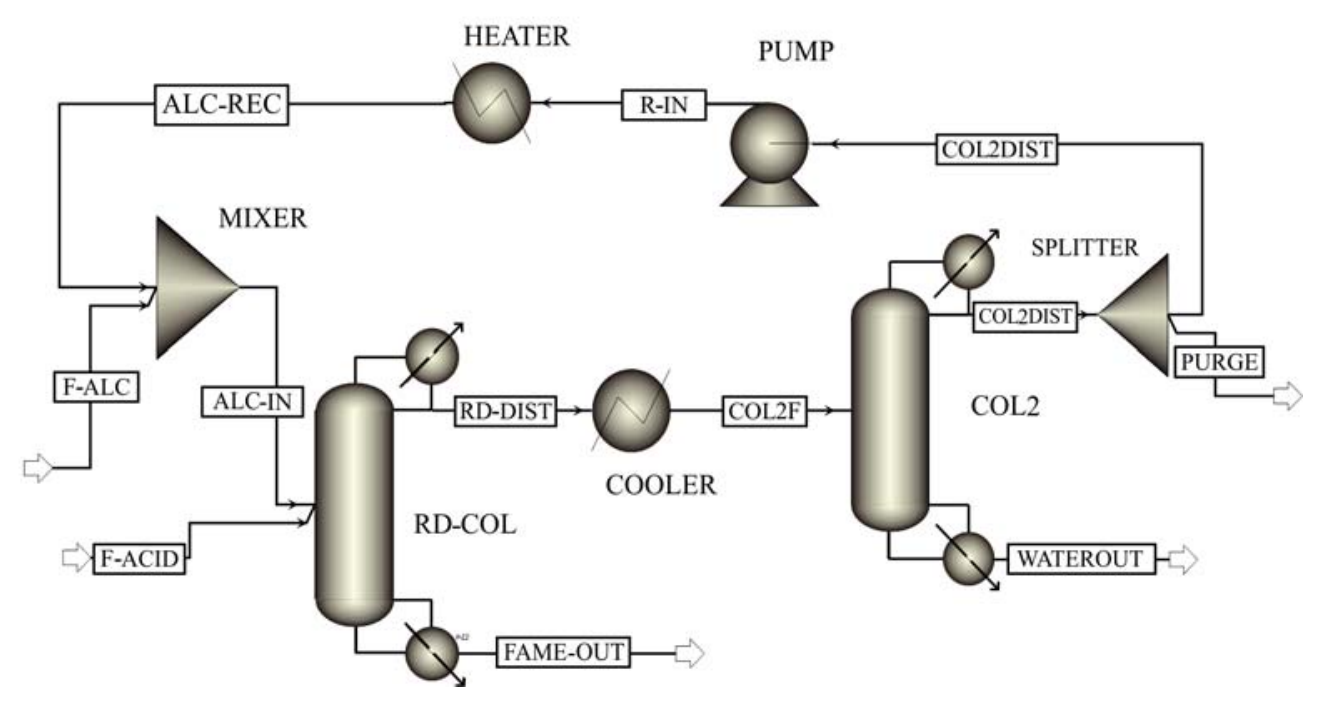

Figure 2. Process flow diagram of biodiesel production process for Case B

while the liquid hold up of all reactive stages was similar as 201 . Please note that few parameters like number of stages, reactive stages were fixed as independent variables, while other parameters like column diameter and height were calculated using independent parameters and model equations so that degree of freedom is 0 . Other process parameters which were distinct for both processes are reported in Table 2, the first column for Case A and second column for Case B respectively. Two process parameters need to be specified here, the other two parameters are calculated by the model equations. To this end, rigorous sensitivity and optimization analyses are performed to maximize biodiesel molar flow and composition in both cases. Various process parameters were varied to achieve the required process targets as part of optimization strategy. The location of methanol and FFA feed inputs were varied at different tray positions so that maximum FAME yield is attained. The lighter feed, methanol, was fed below the reacting section below stage 15, while dodecanoic acid (FFA) entered the RD column above the reacting section above stage 6 . The number of stages and reflux ratio were optimized as well to achieve an efficient and economic design configuration of RD process. The other parameters varied in the optimization approach were feed conditions, $\mathrm{D} / \mathrm{F}$ ratio, reboiler duty. The optimization procedure and criteria are discussed in detail in other work ${ }^{7}$.

\section{PROCESS DESCRIPTION}

The reaction scheme for the production of FAME through esterification reaction can be written as:

$\mathrm{C}_{11} \mathrm{H}_{23}-\mathrm{COOH}+\mathrm{CH}_{3}-\mathrm{OH} \rightleftharpoons \mathrm{C}_{11} \mathrm{H}_{23}-\mathrm{COO}-\mathrm{CH}_{3}+\mathrm{H}_{2} \mathrm{O}$

The molecular weight and boiling point of the components are reported in Table 3 according to their decreasing volatility. The lighter components, water and unreacted methanol is recovered at the top through distillate of RD column while the FAME and unreacted FFA (traces) is recovered at the bottom.

The reactive distillation comprises of three sections: Rectifying section at the top followed by reaction section and the stripping section. The schematic of RD column is drawn in Fig. 3. The reaction of lauric acid and methanol occurs at liquid phase in reaction section, which produces FAME and water. In addition, separation of water from liquid phase occurred simultaneously which promoted the forward reaction and restrained the backward reaction and hence high reaction conversion of acid was achieved. The phenomenon is clearly visible in Fig. 4 and Fig. 5 which show tray wise components

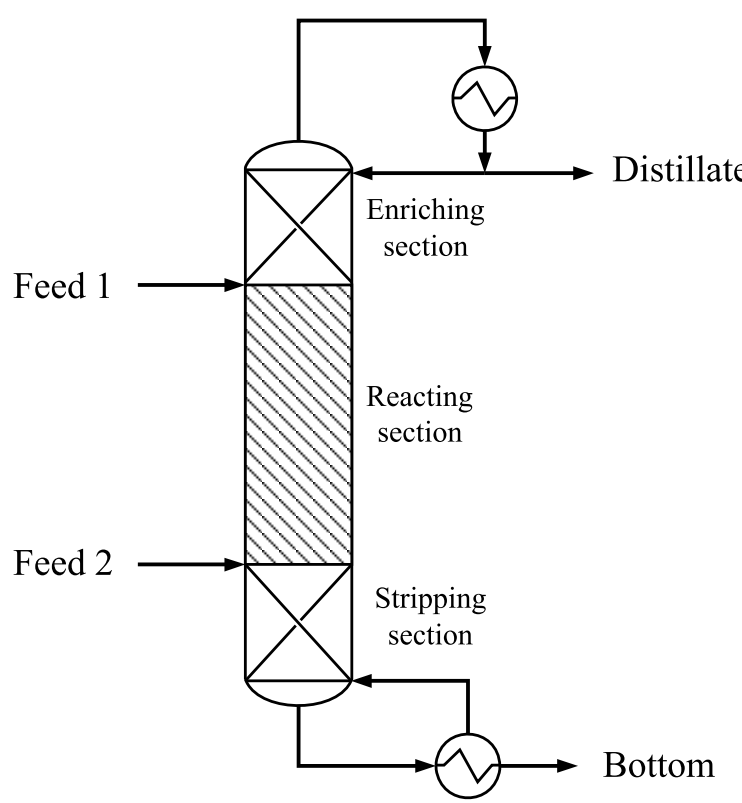

Figure 3. Schematic of RD column

Table 2. Columns configurations of biodiesel production process which varied for Case A and Case B

\begin{tabular}{|l|c|c|c|c|}
\hline \multirow{2}{*}{} & \multicolumn{2}{|c|}{ Case A } & \multicolumn{2}{c|}{ Case B } \\
\cline { 2 - 5 } & RD col. & Col. 2 & RD col. & Col. 2 \\
\hline Reboiler duty $[\mathrm{kW}]$ & 308 & 251.78 & 355 & -216.88 \\
\hline Condenser duty $[\mathrm{kW}]$ & -204.67 & -233.48 & -237.62 & 20.43 \\
\hline Net energy required $[\mathrm{kW}]$ & 103.33 & 18.3 & 117.38 & 1.05 \\
\hline Reflux ratio & 0.8 & 4.0 & 0.65 & 3.0 \\
\hline D/F ratio & 0.636 & 0.445 & & 0.48 \\
\hline Split fraction & \multicolumn{2}{|c|}{$0.0 \%$} & & $8.0 \%$ \\
\hline
\end{tabular}


a)

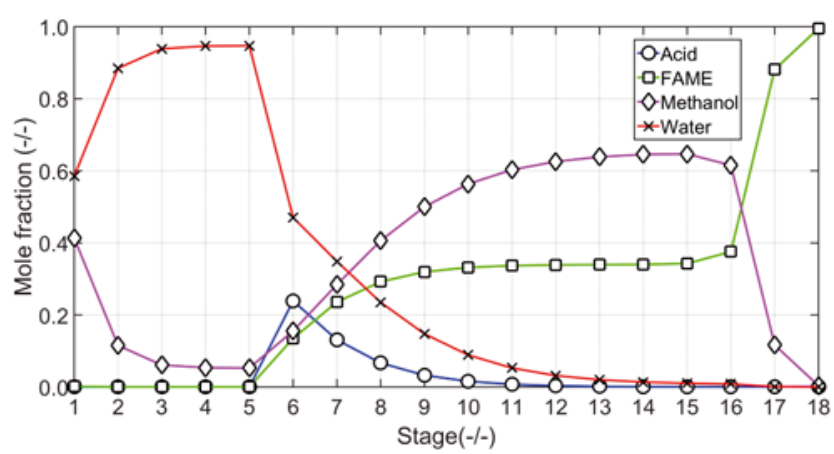

b)

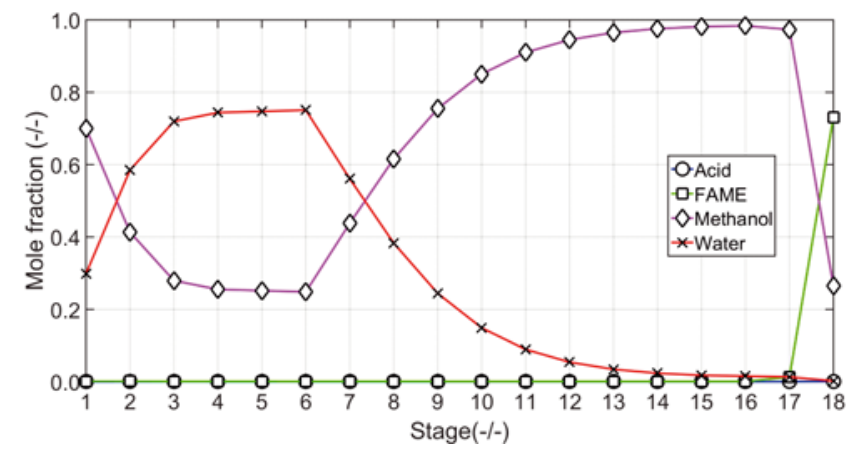

Figure 4. Composition profiles of RD column for case A; (a) Liquid; (b) Vapor

a)

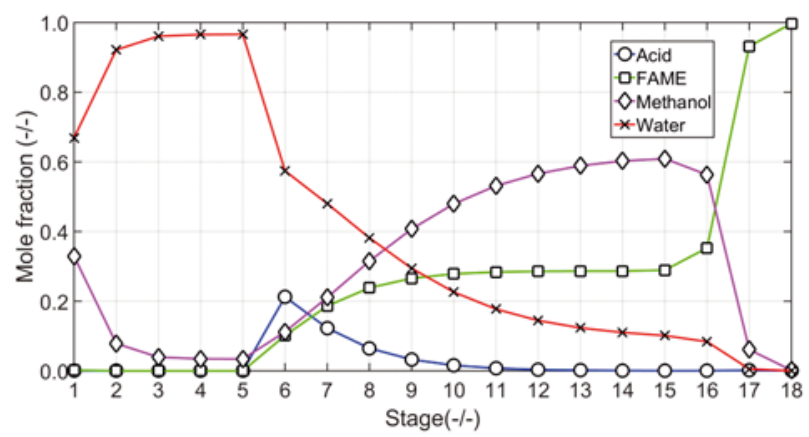

b)

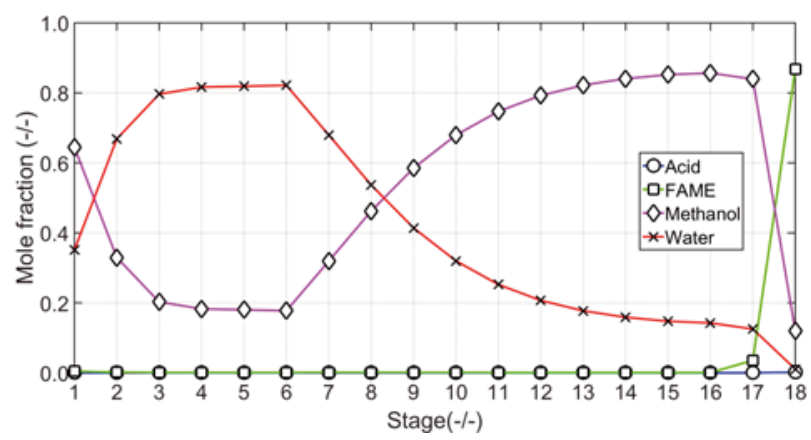

Figure 5. Composition profiles of RD column for case B; (a) Liquid; (b) Vapor

composition profile of liquid and vapor in RD columns in Case A and Case B. It should be noted here that tray 1 is condenser and last tray is the reboiler. The liquid flowing down to stripping section mainly contains FAME and unreacted methanol and traces of lauric acid, after reaction. At the stripping section, lighter components are stripped of liquid and transferred to vapor which thereby increase composition of FAME in liquid. The liquid phase further gets enriched with FAME in the reboiler due to its high boiling point and hence, FAME of high purity is collected at bottom. In the rectifying section at the top of column, the reflux liquid coming down mainly consists of methanol and water and lighter component is transferred from vapor to liquid and recovered at the distillate. Henceforth, the methanol water is separated in the second column. The composition profiles of second column for Case A and Case B are plotted in Fig. 6. The temperature profiles are plotted in Fig. 7. Figure $7 \mathrm{a}$ indicates that RD column in both cases operate at same temperature range while the temperature range is higher for second column in Case B as seen in Fig. 7b. However, the net energy required by column 2 is identical in both cases as reported in Table 2. The energy

a)

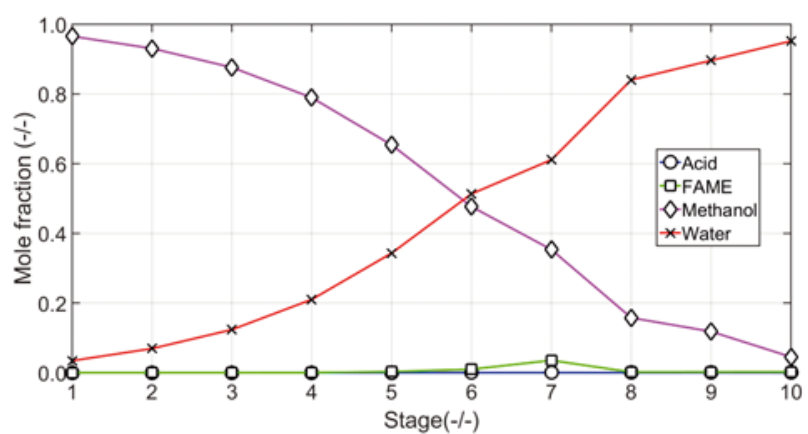

b)

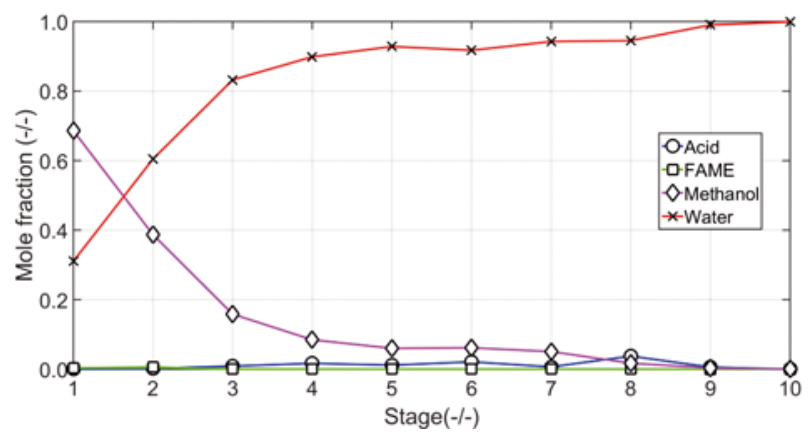

Figure 6. Composition profiles of Column 2; (a) Case A; (b) Case B

a)

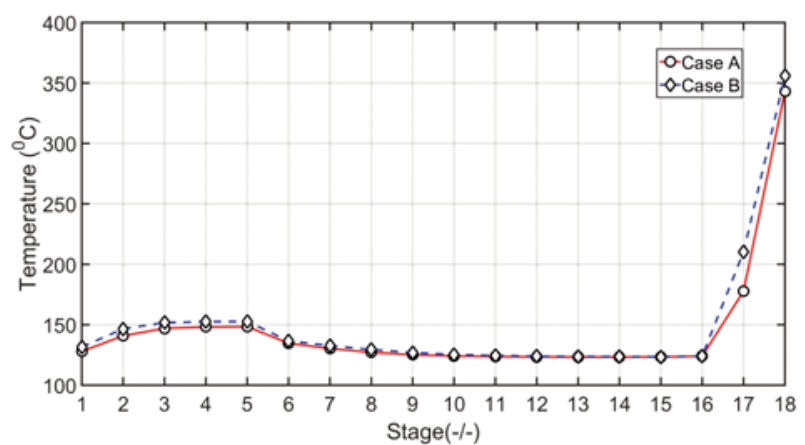

b)

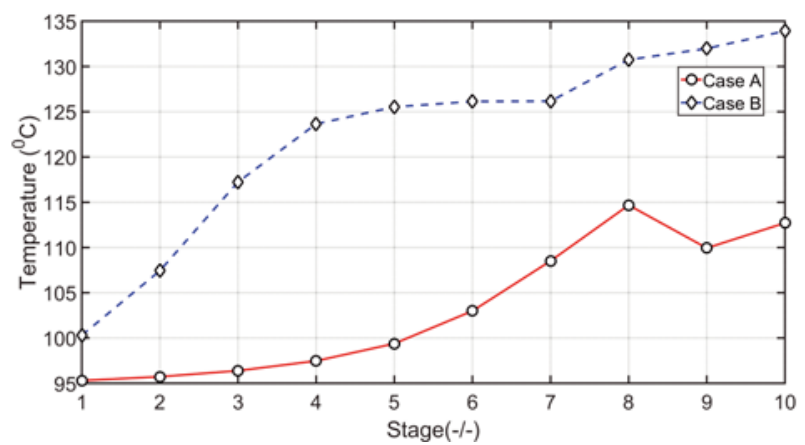

Figure 7. Temperature profiles; (a) RD column; (b) Column 2 
requirement of RD column in Case B is slightly higher than Case A.

The reaction kinetics of the present esterification reaction is given as:

$r=k_{1} C_{C_{11} \mathrm{H}_{23} \mathrm{COOH}} C_{\mathrm{CH}_{3} \mathrm{OH}}-k_{2} C_{\mathrm{C}_{11} \mathrm{H}_{23} \mathrm{COOCH}_{3}} \mathrm{C}_{\mathrm{H}_{2} \mathrm{O}}$

However, since the byproduct water is continuously removed from the reactive system, the reaction always proceeds towards forward reaction. The rate of backward reaction is remarkably slow as compared to forward reaction and, hence, the rate of backward reaction can be neglected from the reaction kinetics. Therefore, the reaction kinetics can be written as ${ }^{13}$ :

$r=A e^{\left(-E_{a} / R_{R T}\right)} C_{C_{11} H_{23} \mathrm{COOH}} C_{\mathrm{CH}_{3} \mathrm{OH}}$

where

A $($ Arrhenius factor $)=120000 \mathrm{~m}^{3} /(\mathrm{kmol} . \mathrm{s}) ; \mathrm{E}_{\mathrm{a}}$ (Activation energy) $=55000 \mathrm{~J} / \mathrm{mol}$

Solid acid catalyst, sulfated zirconia is used for esterification reaction here ${ }^{28}$.

The thermodynamic activity model 'UNIQUAC' is used in the present work for VLE, LLE calculations. The UNIQUAC model is given $\mathrm{as}^{29}$ :

$\ln \gamma_{i}=\ln \frac{\Phi_{i}}{x_{i}}+\frac{z}{2} q_{i} \ln \frac{\theta_{i}}{\Phi_{i}}-q_{i}^{\prime} \ln t_{i}^{\prime}-q_{i}^{\prime} \sum_{j} \frac{\theta_{j}^{\prime} \tau_{i j}}{t_{j}^{\prime}}+l_{i}+q_{i}^{\prime}-\frac{\Phi_{i}}{x_{i}} \sum_{j} x_{j} l_{j}$

The binary interaction parameters used in the activity model is listed in Table 4. Please note that only lauric acid - FAME and methanol-water parameters were present in Aspen properties. The other binary parameters were taken from relevant literature ${ }^{30}$.

The following assumptions were considered to simulate the biodiesel process:

- The liquid and vapor streams exiting any column tray are in equilibrium with each other.
- The liquid and vapor in the stage are completely mixed.

- The liquid phase is homogenous in each stage.

- The vapor hold up in the stage is negligible as compared to the liquid hold up in all trays.

\section{RESULTS AND DISCUSSION}

\section{Case A}

The stream results of Case A are reported in Table 5. In this case. all the distillate from second column which consist of methanol and water in the ratio of $68.5 \mathrm{~mol} \%$ and $31.1 \mathrm{~mol} \%$ is recycled back and mixed with fresh methanol as RD column feed (Fig. 1). The FAME purity at FAME-OUT stream, which is the bottom stream of $\mathrm{RD}$ column is $99.5 \mathrm{~mol} \%$. The RD column distillate, RD-DIST, contains $0.1 \%$ of FAME, which accounts to marginal molar flow of $0.01 \mathrm{kmol} / \mathrm{hr}$, which signifies that almost all the FAME produced is collected at FAME-OUT stream, but only traces are recycled. The WATER-OUT stream, which is the bottom stream of second column bottom, consists $95.2 \%$ water while the rest is methanol. The methanol flow rate at WATER-OUT stream is $0.283 \mathrm{kmol} / \mathrm{hr}$, which is lost by the process. The byproduct obtained from WATER-OUT stream needs to be further treated in the water treatment plant in order to be discharged as wastewater or reuse it in process plant due to high methanol composition, thereby complying the environment safety standards and requirements ${ }^{31}$. Other output scenarios are also possible by changing the input process parameters of RD-column and second distillation column. Two such process configuration alternatives are reported in Table 6 as Case II and Case III. Case I has

Table 3. Physical properties of components

\begin{tabular}{|l|c|c|c|c|}
\hline & Methanol & Water & FAME & Acid \\
\hline Molecular weight & 32 & 18 & 214 & 200 \\
\hline Boiling point $\left({ }^{\circ} \mathrm{C}\right)$ & 64.7 & 100 & 266.85 & 298.7 \\
\hline
\end{tabular}

Table 4. Thermodynamic parameters of UNIQUAC activity model for binary components

\begin{tabular}{|l|c|c|c|c|c|c|}
\hline Comp. i & Acid & Methanol & Methanol & Methanol & Acid & Water \\
\hline Comp. j & FAME & Water & Acid & FAME & Water & FAME \\
\hline$A_{i j}$ & 0 & -1.0662 & 0 & 0 & -0.29924 & 0 \\
\hline$A_{j i}$ & 0 & 0.6437 & 0 & 0 & -0.38437 & 0 \\
\hline$B_{i j}$ & 238.8469 & 432.8785 & 48.3493 & 31.789 & -195.44 & -216.733 \\
\hline$B_{j i}$ & -369.561 & -322.1312 & -309.554 & -539.979 & -107.62 & -658.816 \\
\hline
\end{tabular}

Table 5. Stream results for Case A

\begin{tabular}{|l|c|c|c|c|c|c|c|}
\hline Stream Name & F-ACID & F-ALC & FAME-OUT & RD-DIST & COL2F & WATEROUT & COL2DIST \\
\hline Temperature [ $\left.{ }^{\circ} \mathrm{C}\right]$ & 130 & 120 & 345.0 & 129.2 & 50.0 & 113.2 & 95.5 \\
\hline Pressure [bar] & 6.04 & 6.1 & 6.1 & 6.0 & 4.1 & 3.1 & 3.0 \\
\hline Vapor Fraction & 0 & 1 & 0 & 0 & 0 & 0 & 0 \\
\hline Molar Enthalpy [kJ/mol] & -689.5 & -196.4 & -514.8 & -257.2 & -265.4 & -277.6 & -232.5 \\
\hline Mole Flows [kmo/hr] & 6 & 6.3 & 6.01 & 10.49 & 10.49 & 6.29 & 4.20 \\
\hline Mole Fractions [-/-] & & & & & & & \\
\hline ACID & 1 & 0 & 0.001 & 0.000 & 0.000 & 0.000 & 0.000 \\
\hline FAME & 0 & 0 & 0.995 & 0.001 & 0.001 & 0.002 & 0.000 \\
\hline METHANOL & 0 & 1 & 0.004 & 0.413 & 0.413 & 0.045 & 0.966 \\
\hline WATER & 0 & 0 & 0.000 & 0.585 & 0.585 & 0.952 & 0.034 \\
\hline Mass Flows [kg/hr] & 1201.93 & 201.87 & 1283.21 & 253.01 & 253.01 & 120.58 & 132.43 \\
\hline Mass Fractions [-/-] & & & & & & & \\
\hline ACID & 1 & 0 & 0.001 & 0.001 & 0.001 & 0.002 & 0.000 \\
\hline FAME & 0 & 0 & 0.998 & 0.013 & 0.013 & 0.026 & 0.000 \\
\hline METHANOL & 0 & 1 & 0.001 & 0.549 & 0.549 & 0.076 & 0.980 \\
\hline WATER & 0 & 0 & 0.000 & 0.437 & 0.437 & 0.895 & 0.020 \\
\hline
\end{tabular}


Table 6. Different process configuration alternatives for Case A

\begin{tabular}{|l|c|c|c|}
\hline & Case I & Case II & Case III \\
\hline RD-RR & 0.8 & 1.1 & 1.1 \\
\hline RD reb. duty [kW] & 308 & 250 & 250 \\
\hline Col2-RR & 4.0 & 3.0 & 3.0 \\
\hline Col2-D/F ratio & 0.445 & 0.5 & 0.4 \\
\hline
\end{tabular}

same process parameters and output results as Case A discussed above. The stream composition results of two output streams FAME-OUT and WATER-OUT are reported in Table 7 for Case II and Case III. Although WATER-OUT stream comprises $100 \%$ water for Case II that could be directly used for other purposes without any further treatment and purification processes but the purity of FAME has been compromised. The FAME composition in FAME-OUT stream is $92.3 \%$, which makes the process infeasible since the desired purity is not achieved which is a process requirement. In case III configuration, the FAME and water purity is $97.2 \%$ and $97.3 \%$ respectively, which again does not meet the product quality required and water treatment is required as well. The process configuration in Case III is unsuitable too. Therefore, with the present flowsheet scenario of Case A, Case I could be implemented to produce FAME with $99.5 \%$ composition, however, at the expense of treatment process of byproduct coming out of second column of process flowsheet. coming out of WATER-OUT is $5.85 \mathrm{kmol} / \mathrm{hr}$, which is $77.8 \mathrm{~mol} \%$ of the total water produced during the esterification reaction in RD column. The unreacted methanol is separated in second column and comes out from the distillate 'COL2DIST' stream along with remaining $22.2 \mathrm{~mol} \%$ water. The methanol flowrate in the purge stream is $0.295 \mathrm{kmol} / \mathrm{hr}$, which is minimal, while the rest is recycled to RD column. Please note that $0.283 \mathrm{kmol} / \mathrm{hr}$ of methanol exits with water from process in Case A as well. Hence, employing a small modification in Case A process flowsheet has helped to achieve $77.8 \%$ of pure water from the process, which can be reused directly in any process, without any further water treatment. The methanol-water mixture with $0.685 / 0.311$ molar ratio can be used in other processes, where dilute concentration of methanol in water are required. Moreover, purge flow rate of $0.43 \mathrm{kmol} / \mathrm{hr}$ is minimal as compared to the whole process.

In order to further simplify the process control requisites, the methanol feed flow rate was set at $10 \%$ in excess than acid feed flow rate i.e. at $6.6 \mathrm{kmol} / \mathrm{hr}$. The stream results are reported in Table 9. The results are similar as Case B. However, the purge is increased to $16 \%$, which means more unreacted methanol is lost by the process. Hence, an optimum process has to be chosen, which has a simplified control system strategy as well as lesser loss of unreacted methanol from the system.

Table 7. Stream results of different process alternatives of Case A

\begin{tabular}{|l|c|c|c|c|c|c|}
\hline \multirow{2}{*}{ Mole fraction [-I-] } & \multicolumn{2}{|c|}{ Case I } & \multicolumn{2}{c|}{ Case II } & \multicolumn{2}{c|}{ Case III } \\
\cline { 2 - 7 } & FAME-OUT & WATER-OUT & FAME-OUT & WATER-OUT & \multicolumn{2}{c|}{ FAME-OUT } \\
\hline ACID & 0.001 & 0.000 & 0.002 & 0.000 & 0.001 & 0.000 \\
\hline FAME & 0.995 & 0.002 & 0.923 & 0.000 & 0.972 & 0.003 \\
\hline METHANOL & 0.004 & 0.045 & 0.048 & 0.000 & 0.026 & 0.024 \\
\hline WATER & 0.000 & 0.952 & 0.026 & 1.000 & 0.001 & 0.973 \\
\hline
\end{tabular}

Table 8. Stream results for Case B

\begin{tabular}{|l|c|c|c|c|c|c|c|c|}
\hline Stream Name & F-ACID & F-ALC & $\begin{array}{c}\text { FAME- } \\
\text { OUT }\end{array}$ & RD-DIST & COL2F & $\begin{array}{c}\text { WATERO } \\
\text { UT }\end{array}$ & COL2DIST & PURGE \\
\hline Temperature $\left[{ }^{0} \mathrm{C}\right]$ & 130.0 & 120.0 & 355.8 & 131.7 & 50.0 & 133.9 & 100.3 & 100.3 \\
\hline Pressure $[\mathrm{bar}]$ & 6.0 & 6.1 & 6.1 & 6.0 & 4.1 & 3.1 & 3.0 & 3.0 \\
\hline Vapor Fraction & 0 & 1 & 0 & 0 & 0 & 0 & 0 & 0 \\
\hline Molar Enthalpy [kJ/mol] & -689.5 & -196.4 & -507.7 & -261.3 & -269.5 & -277.2 & -247.5 & -247.5 \\
\hline Mole Flows [kmol/hr] & 6.00 & 6.30 & 6.01 & 11.27 & 11.27 & 5.86 & 5.41 & 0.43 \\
\hline Mole Fractions [-/-] & & & & & & & & \\
\hline ACID & 1.000 & 0.000 & 0.001 & 0.000 & 0.000 & 0.000 & 0.000 & 0.000 \\
\hline FAME & 0.000 & 0.000 & 0.997 & 0.002 & 0.002 & 0.000 & 0.004 & 0.004 \\
\hline METHANOL & 0.000 & 1.000 & 0.002 & 0.329 & 0.329 & 0.001 & 0.685 & 0.685 \\
\hline WATER & 0.000 & 0.000 & 0.000 & 0.669 & 0.669 & 0.999 & 0.311 & 0.311 \\
\hline Mass Flows [kg/hr] & 1201.93 & 201.87 & 1285.53 & 259.25 & 259.25 & 106.00 & 153.25 & 12.26 \\
\hline Mass Fractions [-/-] & & & & & & & & \\
\hline ACID & 1.000 & 0.000 & 0.001 & 0.002 & 0.002 & 0.004 & 0.000 & 0.000 \\
\hline FAME & 0.000 & 0.000 & 0.999 & 0.016 & 0.016 & 0.000 & 0.027 & 0.027 \\
\hline METHANOL & 0.000 & 1.000 & 0.000 & 0.459 & 0.459 & 0.001 & 0.775 & 0.775 \\
\hline WATER & 0.000 & 0.000 & 0.000 & 0.524 & 0.524 & 0.995 & 0.198 & 0.198 \\
\hline
\end{tabular}

\section{Case B}

The process flowsheet in Case B (Fig. 2) comprises of a splitter that splits $8 \%$ of total flow of recycle steam as purge and recycles the remaining effluent to fresh methanol feed. The stream results for Case B is reported in Table 8. It can be clearly seen that high purity of $99.7 \%$ FAME is attained at FAME-OUT stream. Moreover, the water coming out of WATER-OUT is $99.9 \%$ in composition. The total mole flow of water
Table 9. Comparison of stream results with 5\% and $10 \%$ extra methanol feed

\begin{tabular}{|l|c|c|c|c|}
\hline $\begin{array}{l}\text { Methanol input } \\
{[\mathrm{kmol} / \mathrm{hr}]}\end{array}$ & \multicolumn{2}{|c|}{6.3} & \multicolumn{2}{c|}{6.6} \\
\hline $\begin{array}{l}\text { Mole fraction } \\
{[-/-]}\end{array}$ & $\begin{array}{c}\text { FAME- } \\
\text { OUT }\end{array}$ & $\begin{array}{c}\text { WATER- } \\
\text { OUT }\end{array}$ & $\begin{array}{c}\text { FAME- } \\
\text { OUT }\end{array}$ & $\begin{array}{c}\text { WATER- } \\
\text { OUT }\end{array}$ \\
\hline ACID & 0.001 & 0.000 & 0.002 & 0.000 \\
\hline FAME & 0.997 & 0.000 & 0.995 & 0.000 \\
\hline METHANOL & 0.002 & 0.001 & 0.004 & 0.001 \\
\hline WATER & 0.000 & 0.999 & 0.000 & 0.999 \\
\hline Purge & \multicolumn{3}{|c|}{$8.0 \%$} & \multicolumn{2}{c|}{$16.0 \%$} \\
\hline
\end{tabular}




\section{CONCLUSION}

The proposed process flowsheets in Case A and Case B yielded biodiesel product of $99.5 \%$ purity. The three different configurations were studied under Case A, with complete recycle of unreacted methanol. The FAME obtained in the product consisted of $99.5 \%$, $92.3 \%$ and $97.2 \%$ respectively in mole basis. Although, the first configuration of Case A has $99.5 \%$ biodiesel composition in product stream, the byproduct stream consists of $95.2 \%$ water, which needs to be further treated for other purposes. In Case B, when $8 \%$ of recycle is split as purge, the product stream consists of 99.7 mol\% biodiesel while the byproduct stream comprises of $99.9 \mathrm{~mol} \%$ water, which constitutes $77.8 \%$ of total water produced in reaction process. The purge flow is $0.43 \mathrm{kmol} / \mathrm{hr}$, which is marginal compared to other process flows, albeit the methanol composition is 68.5 mol\% in purge. The proposed process flowsheet in Case $\mathrm{B}$ can significantly enhance the biodiesel yield and purity while recovering reusable water at byproduct stream.

\section{ACKNOWLEDGEMENT}

The authors are grateful to Deanship of Scientific Research at King Faisal University for supporting and funding this work through Nasher Research project no. 186075.

\section{LITERATURE CITED}

1. Hosseinzadeh-Bandbafha, H., Tabatabaei, M., Aghbashlo, M., Khanali, M. \& Demirbas, A. (2018). A comprehensive review on the environmental impacts of diesel/biodiesel additives. Energy Convers. Manage. 174, 579-614.

2. Veljković, V.B., Biberdžić, M.O., Banković-Ilić, I.B., Djalović, I.G., Tasić, M.B., Nježić, Z.B. \& Stamenković, O.S. (2018). Biodiesel production from corn oil: A review. Renewable Sustainable Energy Rev. 91, 531-548.

3. Atadashi, I.M., Aroua, M.K. \& Aziz, A.A. (2011). Biodiesel separation and purification: A review. Renewable Energy 36(2), 437-443.

4. Thangaraj, B., Solomon, P.R., Muniyandi, B., Ranganathan, S. \& Lin, L. (2018). Catalysis in biodiesel production-a review. Clean Energy 10.1093/ce/zky020, zky020-zky020.

5. Bateni, H., Saraeian, A., Able, C. \& Karimi, K. (2019). Biodiesel Purification and Upgrading Technologies In M. Tabatabaei \& M. Aghbashlo (Eds), Biodiesel: From Production to Combustion (pp. 57-100). Basel. Switzerland: Springer, Cham.

6. Ambat, I., Srivastava, V. \& Sillanpää, M. (2018). Recent advancement in biodiesel production methodologies using various feedstock: A review. Renewable Sustainable Energy Rev. 90, 356-369.

7. Ali, S.S., Hossain, S.S. \& Asif, M. (2017). Dynamic modeling of the isoamyl acetate reactive distillation process. Pol. J. Chem. Technol. 19(1), 59.

8. Tuchlenski, A., Beckmann, A., Reusch, D., Düssel, R., Weidlich, U. \& Janowsky, R. (2001). Reactive distillation industrial applications, process design \&amp; scale-up. Chem. Eng. Sci. 56(2), 387-394.

9. Estrada-Villagrana, A.D., Quiroz-Sosa, G.B., Jiménez-Alarcón, M.L., Alemán-Vázquez, L.O. \& Cano-Domínguez, J.L. (2006). Comparison between a conventional process and reactive distillation for naphtha hydrodesulfurization. Chem. Eng. Process. Process Intensif. 45(12), 1036-1040.

10. Guo, B. \& Li, Y. (2012). Analysis and simulation of reactive distillation for gasoline alkylation desulfurization. Chem. Eng. Sci. 72, 115-125.
11. Hasabnis, A. \& Mahajani, S. (2014). Acetalization of Glycerol with Formaldehyde by Reactive Distillation. Ind. Eng. Chem. Res. 53(31), 12279-12287.

12. Chandrakar, A., Agarwal, V., Chand, S. \& Wasewar, K.L. (2007). Modeling and Simulation of Catalytic Distillation Column for Esterification of Acetic Acid with Methanol. Int. J. Chem. Reactor Eng. 5(1), 481.

13. Kiss, A.A. (2011). Heat-integrated reactive distillation process for synthesis of fatty esters. Fuel Process. Technol. 92(7), 1288-1296.

14. Agarwal, M., Singh, K. \& Chaurasia, S.P. (2012). Simulation and sensitivity analysis for biodiesel production in a reactive distillation column. Pol. J. Chem. Technol. 14(3), 59.

15. Nguyen, N. \& Demirel, Y. (2011). Using thermally coupled reactive distillation columns in biodiesel production. Energy 36(8), 4838-4847.

16. Poddar, T., Jagannath, A. \& Almansoori, A. (2017). Use of reactive distillation in biodiesel production: A simulation-based comparison of energy requirements and profitability indicators. Appl. Energ. 185, 985-997.

17. Kianimanesh, H.R., Abbaspour-Aghdam, F. \& Derakhshan, M.V. (2017). Biodiesel production from vegetable oil: Process design, evaluation and optimization. Pol. J. Chem. Technol. 19(3), 49.

18. Kiss, A.A., Omota, F., Dimian, A.C. \& Rothenberg, G. (2006). The heterogeneous advantage: biodiesel by catalytic reactive distillation. Top. Catal. 40(1), 141-150.

19. Machado, G.D., de Souza, T.L., Aranda, D.A.G., Pessoa, F.L.P., Castier, M., Cabral, V.F. \& Cardozo-Filho, L. (2016). Computer simulation of biodiesel production by hydro-esterification. Chem. Eng. Process. Process Intensif. 103, 37-45.

20. Bildea, C.S. \& Kiss, A.A. (2011). Dynamics and control of a biodiesel process by reactive absorption. Chem. Enginee. Res. Des. 89(2), 187-196.

21. Dimian, A.C., Bildea, C.S., Omota, F. \& Kiss, A.A. (2009). Innovative process for fatty acid esters by dual reactive distillation. Comput. Chem. Eng. 33(3), 743-750.

22. Pérez-Cisneros, E.S., Mena-Espino, X., Rodríguez-López, V., Sales-Cruz, M., Viveros-García, T. \& Lobo-Oehmichen, R. (2016). An integrated reactive distillation process for biodiesel production. Comput. Chem. Eng. 91, 233-246.

23. Gomez-Castro, F.I., Rico-Ramirez, V., Segovia-Hernandez, J.G. \& Hernandez, S. (2010). Feasibility study of a thermally coupled reactive distillation process for biodiesel production. Chem. Eng. Process. Process Intensif. 49(3), 262-269.

24. Luyben, W.L. (2000). Economic and Dynamic Impact of the Use of Excess Reactant in Reactive Distillation Systems. Ind. Eng. Chem. Res. 39(8), 2935-2946.

25. Luyben, W.L. \& Yu, C.C. (2008). Reactive Distillation Design and Control (1st ed.). Hoboken, New Jersey, United States: John Wiley \& Sons.

26. Santori, G., Di Nicola, G., Moglie, M. \& Polonara, F. (2012). A review analyzing the industrial biodiesel production practice starting from vegetable oil refining. Appl. Energ. 92, 109-132.

27. Kiss, A.A., Dimian, A.C. \& Rothenberg, G. (2006). Solid Acid Catalysts for Biodiesel Production - Towards Sustainable Energy. Adv. Synth. Catal. 348(1-2), 75-81.

28. Kiss, A.A., Dimian, A.C. \& Rothenberg, G. (2008). Biodiesel by Catalytic Reactive Distillation Powered by Metal Oxides. Energy Fuels 22(1), 598-604.

29. Elliott, J.R. \& Lira, C.T. (2012). Introductory Chemical Engineering Thermodynamics (2nd ed.). New Jersey, United States: Prentice Hall.

30. Omota, F., Dimian, A.C. \& Bliek, A. (2003). Fatty acid esterification by reactive distillation. Part 1: equilibrium-based design. Chem. Eng. Sci. 58(14), 3159-3174.

31. Babbitt, C.W., Pacheco, A. \& Lindner, A.S. (2009). Methanol removal efficiency and bacterial diversity of an activated carbon biofilter. Bioresour. Technol. 100(24), 6207-6216. 